\title{
Dynamic Assessment in Combination with Video Interaction Guidance in Preschool Education
}

\author{
Kristýna Krejčová ${ }^{1}$ \\ ${ }^{1}$ Department of Economic Teaching Methodology, University of Economics, Prague, Czech Republic \\ Correspondence: Kristýna Krejčová, Department of Economic Teaching Methodology, University of Economics, \\ W. Churchill Sq. 4, 13067 Prague 3, Czech Republic. Tel: 420-224-095-134. E-mail: kris.krejcova@gmail.com
}

\author{
Received: March 16, 2015 Accepted: April 9, 2015 Online Published: June 29, 2015 \\ doi:10.5539/ies.v8n7p181 URL: http://dx.doi.org/10.5539/ies.v8n7p181
}

\begin{abstract}
Dynamic assessment represents an alternative diagnostic approach focused on the revelation of the tested persons' learning potential. The learning potential is observed via the emphasis on the achievement process. It aims at meaningful connection with the intervention that immediately applies diagnostic findings to support the development of an individual's abilities.

This article summarizes essential information about the mentioned diagnostic trend and investigates possibilities of its utilization in a combination with the method of video interaction guidance (VIG). The pilot-study evaluating this combination of dynamic assessment and VIG has been conducted in three stages. Both quantitative and qualitative methods have been used, although the nature of the study is mostly qualitative. The study verifies the utility and advantages of the dynamic assessment-based method for preschool preparation in kindergartens. Moreover, the paper identifies effective instructions and styles of communication supporting cognitive development.
\end{abstract}

Keywords: dynamic assessment, video interaction guidance, school maturity and readiness, learning potential

\section{Introduction}

\subsection{Dynamic Assessment}

The term dynamic assessment refers to a subset of interactive diagnostic methods including planned mediational teaching and the assessment of the impact of that teaching on subsequent performance (Haywood \& Tzuriel, 2002, p. 40). The mediational teaching mostly involves teaching (or "mediating") of metacognitive strategies helping to extend the learning potential of the individual. Definitions of the dynamic assessment (e.g. Kozulin \& Garb, 2004; Sternberg \& Grigorenko, 2002) have two constant aspects-active intervention by examiners and assessment of the response to intervention, which means the effect of mediational learning (Haywood \& Lidz, 2007, p. 1).

The dynamic assessment of learning potential significantly differs from traditional assessment of intelligence (static assessment). Standard intellectual testing presumes that the manifested level of functioning reveals the inner abilities of the individual more or less accurately, unaided performance is the best format for assessment and the goal of testing is to predict the future functioning. From the point of view of the dynamic assessment, cognitive processes are highly modifiable (therefore this type of assessment focuses on the degree of modifiability rather than on the manifest level of functioning). The next point of the paradigm of dynamic assessment is that interactive assessment including the learning phase provides a better insight into learning capacities than unaided performance (Kozulin, 2003, p. 103).

An extremely important context of differences between the static and dynamic assessment is the fundamental discrepancy between intelligence and cognition (cognitive and metacognitive processes). Intelligence is primarily genetic, whereas cognitive processes must be acquired. In consequence, intelligence itself is not treatable, whereas systematic cognition is eminently modifiable. (Haywood \& Lidz, 2007, p. 25)

Dynamic assessment is strongly connected with intervention. The goal of the testing process is the identification of obstacles to learning and performance and estimation of investment required to overcome the obstacles. The assessment is much more interactive than static assessment that prescribes the examiner to be affectively neutral, to pose problems and record responses only. In the dynamic assessment, the examiner is encouraged to be 
affectively involved. He/she poses problems, identifies obstacles, teaches metacognitive strategies when necessary and promotes change (Haywood \& Lidz, 2007, p. 6).

The theoretical core of the dynamic assessment created the conception of the zone of proximal development (Vygotskij, 1986) and the mediated-learning experience (Feuerstein, Klein, \& Tannenbaum, 1991). Both authors were confident about a modifiability of human mental functioning and about possibility of social environment to significantly improve the learning potential. The mediated learning experience stands for an interactive process in which a mediator (parent, teacher or more capable peer) interposes himself between a child and a world in order to regulate frequency, order, intensity and context of stimuli affecting the child (Feuerstein, Klein \& Tannenbaum, 1991, p. 96). Feuerstein described 12 criteria of mediated learning experience (MLE), the first three of them are crucial and necessary for MLE (mediation for intentionality and reciprocity, mediation for transcendence, mediation for meaning).

There is a large variety of different methods of dynamic assessment, connected by the same philosophical background (Kozulin, 1998) and by three important aspects: the test-intervention-retest arrangement of the test situation; an orientation to the cognitive modifiability and the immediate connection with the intervention (Lidz, 1991).

Authors of dynamic methods do not tend to replace the static assessment of intelligence. The dynamic assessment should be a meaningful alternative of the traditional assessment and should be administrated particularly when results of tests of intelligence seems to be apparently inconsistent with the real potential of an individual (e.g. children coming from a low socioeconomic or culturally different background; emotional or personality disturbance that could affect the achievement in tests of intelligence; learning disabilities).

Because dynamic assessment deals with learning potential and cognitive strategies more than intelligence itself, it is not domain of psychologists and can be administrated by teachers as well. Dynamic assessment could be very enriching for the professional skills of teachers, because it helps them to understand the learning strategies of students. Knowledge of student's learning styles could help teachers to create and apply various instructions with the same materials in order to support all students to achieve learning objectives (Mattarima \& Hamdan, 2011).

\subsection{Video Interaction Guidance}

Dynamic assessment has similar theoretical background as the method of video interaction guidance (VIG). Both methods have been combined in research (Landor, 2006; Strnádková, 2005) because VIG helps to enhance teacher's sensitivity to communication signals of students and to create effective instructions supporting students to develop appropriate cognitive and metacognitive strategies.

The VIG has been developed in the Netherlands (e.g. Jansen \& Wels, 1995, 1998, in Häggman-Laitila et al., 2003) as a short-time intensive method helping to improve interactions between parents and children, practiced by the organization named SPIN (Stichting Promotie Intensieve Thuisbehandeling-Institution of Supporting of Intensive Home Approach) as an alternative to institutionalization of problem children. It was being expanded into many other areas of a social contact-the VIG is used in a very wide range of contexts (education, health service, social work, management etc.).

The method has been inspired by a wide range of theoretical sources from several disciplines-some of the most important are human ethology (Trevarthen-theory of intersubjectivity, reciprocity, proto conversation; Papouschek and Papouschek-intuitive parenting), psychology (Bowlby-attachment theory, Vygotsky-one of the proximal development, Bandura-social learning theory), research of communication (Jacobson - rituals of the contact, Watzlavik-common theories of verbal and nonverbal communication, video feedback et al.), pedagogy (Tausch and Tausch, Rogers-humanistic pedagogy, Gordon-parental ability et al.) (Beaufortová, 2002).

Through the video-records, the method focuses on increasing of the successful interactions, including verbal, nonverbal and paraverbal aspects of the communication. The VIG enables clients to watch themselves from a distance and to have time for assisted self-reflection, with the possibility to stop, review or to slow down the recording (Fukkink \& Tavecchio, 2010, p. 1653).

The impact of the video-feedback on the development of the communication skills has been expressed elaborately in the theory of positive self-modelling by Dowrick and his colleagues (1999, cited in Bidlová, 2005). The theory emphasizes that the positive self-review enables the increase of the adaptive behaviour that has been contaminated by unwanted elements of behaviour, facilitates the transfer of some environment-specific behaviour into another environment, reduces the anxiety etc. (Bidlová, 2005). According to this theory, the VIG trainer selects and labels successful elements of interaction, intending to strengthen the communication skills of 
the client.

The records are analysed according to Principles of the contact-categories of observable elements of behaviour that the VIG trainer and the client try to identify on the record (Biemans, 1990, in Beaufortová, 2002). The knowledge of these principles enables the client to increase his/her communication capability that means having more variants of communication. Wider communication repertoire then increases the probability of an effective communication in every situation (Šilhánová, 2008). This last stage of viewing the recordings, the actual video feedback, is especially important. A detailed and structured analysis of the record using behaviour coding, i.e. focusing on specific behaviours, is important. The videotrainer may stop the edited video at certain moments or may repeat certain fragments occasionally to highlight specific behaviour of the client in interaction with the other members of social system. The videotrainer may focus the attention of the client to highly specific elements of behaviour to highlight the importance of sensitivity, to provide the client feedback or to elicit a discussion (Fukkink, 2008, p. 905).

The VIG clients are taught these principles by video analysis under the guidance of the VIG trainer. The analysis takes place in supportive, productive climate. Clients are guided to identify successful communication principles and to think how to use these principles in other situations. This way of learning is demonstrably more efficient than to only point out and eliminate mistakes. "Based on the social learning theory of Bandura (1997), the VIG assumes that positive reinforcement of positive behaviour increases the self-efficacy of learners"(Fukkink \& Tavecchio, 2010, p. 2).

The goal of the VIG at schools is to help teachers to develop their communication and self-reflection skills. That would enable them to attach relationships with students successfully, to manage the class and the education efficiently and to support their self-confidence in the role of a teacher.

The basic premise of using the VIG at school is that pedagogical climate in the classroom is created by the teacher. The teacher uses his/her communicational and organizational abilities to influence behaviour and performance of students. Consequently, he/she is greatly responsible for the quality of the interactions in the classroom. If the teacher helps students to work without stress, in relaxed climate, if he/she tries to stimulate them and expresses pleasure from their successes, the teacher creates learning-centred climate (Bidlová, 2005).

The VIG at school uses records of ordinary situations from the education to improve the communication through finding, enriching and strengthening the communication skills of the teacher. The possibility to see himself/herself from the distance, to review or slow down the record and to analyse the behaviour of the teacher and students under the guidance of the VIG trainer gives the teacher a new frame of view on the problem situations and on possible solutions (Šírová \& Krejčová, 2011).

With the help of the VIG trainer, the teacher is appealed to be as active as possible in identifying the elements which make these moments effective, reflecting on their impact on the students and considering how could he/she increase using of this elements of communication. Watching these successful moments, teacher gains confidence in his/her communication sources and in his/her ability to identify own strengths and areas for development (Forsyth, 2008).

The effectiveness of VIG method has been researched by many studies, e.g. Fukkink (2008) made a meta-analytic study of 29 family programmes using VIG, showing statistically significant positive effects of video feedback interventions on the parenting behaviour and attitude of parents and the development of the child.

\subsection{Research Questions}

The evaluative pilot-study has been conducted in three stages, both quantitative and qualitative methods has been used, although the nature of the study is mostly qualitative. The main objective of this study was to verify the utility of the dynamic assessment-based method of the development of the preschool preparation in kindergartens. This objective arises from the intensive need of dynamic assessment as quite new and insufficiently enlarged method to be elaborated and verify by a research (Sternberg \& Grigorenko, 2002; Tzuriel et al., 2001) and from the need to create a method of preschool preparation that would be more orientated on cognitive and metacognitive processes.

Next objective was to identify the effective instructions and styles of communication supporting cognitive development. Methods of dynamic assessment can be approximately divided into two groups: research-orientated and clinical-orientated (Caffrey, D. Fuchs, \& L. Fuchs, 2008). The method elaborated and verified in this study belongs to the clinical-orientated group, therefore it is important to focus on interactional aspects of application of dynamic assessment. 
The study should answer three major questions:

1) Which principles of dynamic assessment are crucial for diagnostic and intervention in kindergartens?

2) How effective is the dynamic assessment-based preschool preparation compared with common methods?

3) How can be the VIG method used in kindergarten to support dynamic assessment-based preschool preparation?

\section{Method}

\subsection{Research Design}

At the first stage of the research, school maturity of two groups has been compared as the dependent variable. Both groups were tested at the beginning and at the end of their last school year in kindergarten. In the experimental group the dynamic assessment-based method of the preschool preparation has been conducted (independent variable). In the control group there was a common method of preschool preparation-mostly focused on graphomotorics, less attention given to visual perception, pre-math skills, almost ignored auditory perception, cognitive and metacognitive processes. In both groups, differences between styles of preschool preparation were studied by way of observation and interviews with teachers.

At the second stage, the dynamic-assessment based method of school preparation has been combined with the video-interaction guidance to enhance teacher's sensitivity to the communication signals of children and to create effective instructions helping them to develop appropriate cognitive and metacognitive strategies. Also at this stage, school maturity of all participants has been tested at the beginning and at the end of the school year. The second stage took two school years. In the first year, the experimental group with the application of VIG method was compared with the control group without any intervention. In the second year, because of distinctly qualitative orientation of this stage of a research, only the experimental group has been tested and observed.

At the third stage, the stability of changes in educating style of teachers from the second stage bas been monitored after three years. Research design, the allocation of research stages in years and used methods are depicted in Figure 1.

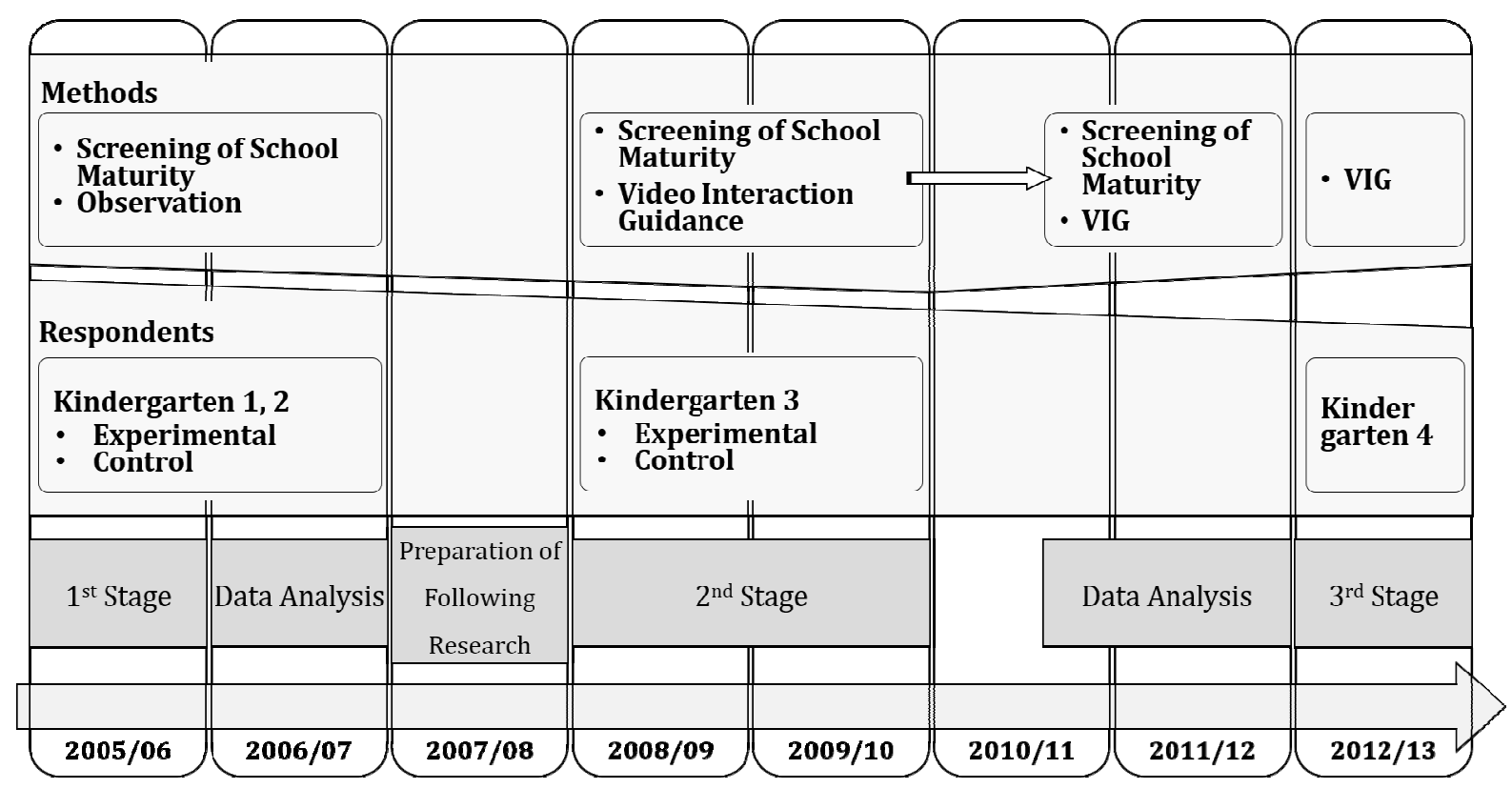

Figure 1. Research design

\subsection{Participant Characteristics}

In the Czech Republic, children are obviously attending kindergarten from the age of 3 years to 6 years (or 7 years in the case of delayed school attendance). In the last year in kindergarten (or last two years in the case of delayed school attendance), a formal preschool preparation is a part of their education. The target population of 
this study were children in the last year of their preschool preparation in kindergarten. The sample size was 111 children between 5 and 7 years from kindergartens that had been selected by convenience sampling. Children weren't randomly assigned into experimental and control groups, due to their fixed placement in classes during the long-term research. Table 1 shows the amount of participant of the research at the beginning and at the end of each stage of the research in the stage 1 and 2 and number of respondents and administrated tests that were involved into the data analysis. The sample size has been reduced by quite high experimental mortality resulted from an optional school attendance in kindergartens in Czech Republic. Regardless, resultant number of respondents still enables to verify significance of the quantitative results and to make useful inferences from the qualitative data.

Table 1. Number of respondents in testing of school maturity

\begin{tabular}{lcccc}
\hline \multicolumn{5}{c}{ Data analysis } \\
\hline & Beginning & End & Respondents & Tests \\
1. stage & 64 & 46 & 40 & 80 \\
2. stage & 21 & 17 & 16 & 32 \\
Total & 85 & 63 & 56 & 112 \\
\hline
\end{tabular}

The method of VIG has been used with two teachers only, because of the qualitative and intensive long-lasting orientation of this part of the research. The learning style of each teacher has been observed and supported by VIG during one school year. Teachers were chosen on the basis of recommendation by the Educational Psychology Service. Both teachers willingly accepted the intervention by VIG method and considered it to be very enriching. The teachers have been recorded in their classes during different activities of the preschool preparation with preschool children. Table 2 summarizes the amount of children present in each recording during the second and third stage of the research and the frequency of recordings in each group.

Table 2. Number of respondents in recordings

\begin{tabular}{lcccc}
\hline & \multicolumn{2}{c}{$2008 / 2009$} & \multicolumn{2}{c}{$2009 / 2010$} \\
\cline { 2 - 5 } & $\begin{array}{c}\text { Number of } \\
\text { participants }\end{array}$ & $\begin{array}{l}\text { Month of } \\
\text { recording }\end{array}$ & $\begin{array}{c}\text { Number of } \\
\text { participants }\end{array}$ & $\begin{array}{c}\text { Month of } \\
\text { recording }\end{array}$ \\
\hline 1. recording & 10 & October 2008 & 10 & September 2009 \\
2. recording & 9 & December 2008 & 10 & September 2009 \\
3. recording & 8 & March 2009 & 12 & October 2009 \\
$\begin{array}{l}\text { Control } \\
\text { recording }\end{array}$ & 8 & September 2012 & 8 & September 2012 \\
\hline
\end{tabular}

\subsection{Procedures and Instrumentation}

School maturity and readiness of all participants has been assessed by the screening method created in the Educational Psychology Service in Prague (Modřany). The method consists of six parts assessing graphomotorics (tasks called Shapes, Writing and Dots), articulation, maturity of visual and auditory perception, visual differentiation and pre-math skills (Šebová, 2004). The same authors designed the dynamic assessment-based method of preschool preparation used in this researched.

We applied the method of VIG in experimental groups in combination with the screening of school maturity, so the design of the study kept the "test-intervention-retest" format of the dynamic assessment..The method of VIG focuses on communication in general. In this research, particular attention was given to communication strategies developing cognitive and metacognitive processes of children. In both school years, three recording with subsequent microanalysis and feedback interviews were executed. Control recordings were applied only once in each group without subsequent interview, because the objective of this step was to verify the time-stability of communication principles acquired by VIG. 


\section{Results}

\subsection{Crucial Principles of Dynamic Assessment in Kindergarten}

The first research question focused on the crucial concept of application dynamic assessment in kindergarten. The effective principles were identified on recordings, their meaning and importance were also discussed during feedback interviews.

Majority of identified principles correspond with the theory of mediated learning approach by Feuerstein (Feuerstein, Klein, \& Tannenbaum, 1991). All three criteria that are essential for mediated learning experience were identified on the recordings (mediation for intentionality and reciprocity, mediation for transcendence, mediation for meaning). Moreover, other two criteria of MLE (mediation for feeling of competence, mediation for self-regulation) are considered as extraordinarily important and used in research with three major criteria e.g. by Tzuriel (2001). Both of these additional criteria were also identified on the recordings.

Table 3 summarizes all principles that had been identified on all recordings during the research. The principles have been divided into three groups: correspondence with the mediated learning experience, other fundamental principles of dynamic assessment and additional principles (elements of communication and didactic application of DA). Majority of principles has been identified repeatedly except mediation for individuation and psychological differentiation that has been used in a special situation (the teacher needed to explain the children some differences in language competences of a Vietnamese girl). However these principles showed as applicable and efficient for the preschool preparation in our study, the role of other criteria of mediated learning experience in this type of education could be subject of subsequent research.

Table 3. Identified principles

\begin{tabular}{lll}
\hline Mediated learning experience & Other basis DA principles & $\begin{array}{l}\text { Additional communication and } \\
\text { didactic principles }\end{array}$ \\
\hline $\begin{array}{l}\text { mediation for intentionality and } \\
\text { reciprocity }\end{array}$ & $\begin{array}{l}\text { orientation on the process } \\
\text { (not only on the results) }\end{array}$ & $\begin{array}{l}\text { more space for thinking and } \\
\text { expressing of a response }\end{array}$ \\
$\begin{array}{l}\text { mediation for transcendence } \\
\text { problem) }\end{array}$ & $\begin{array}{l}\text { learning in the zone of } \\
\text { proximal development }\end{array}$ & designation of cognitive strategies \\
mediation for meaning & & $\begin{array}{l}\text { short communication exchanges } \\
\text { leading children to an effective } \\
\text { control of their work } \\
\text { mediation for feeling of competence }\end{array}$ \\
$\begin{array}{l}\text { mediation for self-regulation } \\
\text { mediation for individuation and } \\
\text { psychological differentiation }\end{array}$ & $\begin{array}{l}\text { correct and false response } \\
\text { acceptance of unordinary solutions }\end{array}$ \\
\hline
\end{tabular}

\subsubsection{Designation of Cognitive Strategy}

This section contains a transcript of selected interviews from research recordings. These passages have been chosen because they refer to some principles of dynamic assessment (introduced in the name of each subheading) that were identified on the recordings. The transcripts have been used in this paper to clarify the identification of the principles of dynamic assessment on recordings.

Situation: Children cut out and glued elements of a house for birds. Teacher wants them to reflect their work.

Teacher: "What was easy for you?"

Child (shows a base).

Teacher: "The base. And what was hard?"

Child: "This." (shows a roof)

Teacher: "The roof. And why do you think that the roof was hard?"

Child: "Because it is sideways." 
Teacher: "Because it is sideways. Actually, you started with the roof and you try to add the base, didn't you?"

\subsubsection{Mediation for Meaning and Transcendence}

Situation: Children have list of pictures and they should circle words with the phone $\mathrm{H}$. The teacher works with a child who came letter and is not familiar with the strategy.

Teacher: "Do you hear the phone H? Say the word HRNEK (cup). And HROZNOVÉ VÍNO (grape)."

Child (repeats words)

Teacher: "Circle the cup. Do you agree with it? And why do you think we circled HLEMÝŽ̌̌ (snail)? You have already circled it."

Child: "Because its first letter is H."

Teacher: "Excellent, because its first letter is H."

\subsubsection{Orientation on the Process}

Situation: Children reflect their graphomotorics task-drawing of clew.

Teacher: "What do you like at this one?"

Child: "It is nicely big."

Teacher: "Nice-and what next?"

Child: "Nicely spin."

Teacher: Nicely spin. And how did you manage to spin it so nicely, what do you think?"

Child: "The hand was relaxed."

Teacher: "Well, your hand was relaxed. And where did you start?"

\subsection{Effectiveness of the Dynamic Assessment-Based Preschool Preparation Compared with Common Methods}

To analyse findings from the examination of school maturity and readiness, methods of descriptive and inductive statistics have been used. Results from descriptive statistic confirm higher efficiency of the dynamic assessment-based preschool preparation. Wilcoxon signed rank test (Wilcoxon, 1945) was applied in data analysis (see Table 4). Despite the progress in total score in experimental group wasn't statistically significant ( $p$ $=0.17$ ), after the division into separate items the test shows that progress in auditory perception was significant on the level significance $\alpha=0.05(Z=-2.27, p=0.02)$.

Table 4. Wilcoxon signed rank test-results

\begin{tabular}{lccccccccc}
\hline & Shapes & Writing & Dots & Pre-math. & Visual perc. & Visual dif. & Auditroyperc. & Articultion & Total \\
\hline Wilcox. & 383.5 & 375.5 & 385 & 326 & 344.5 & 399 & 320 & 371 & 359.5 \\
Z & -0.47 & -0.69 & -0.42 & -0.8 & -1.02 & -0.3 & -2.27 & -0.56 & -1.37 \\
Signif. & 0.65 & 0.50 & 0.69 & 0.48 & 0.32 & 0.78 & 0.02 & 0.59 & 0.17 \\
\hline
\end{tabular}

Table 5 summarizes progress in all tested areas during the school year (arithmetical mean). Scores of both experimental groups and both control groups from research stage 1 and 2 were counted up. Comparing scores from single tasks, there was greater progress in the visual and auditory perception and pre-math skills in experimental groups than in control groups. In the control group, there was more remarkable progress in graphomotorics. These findings show that the experimental group with the dynamic assessment-based preschool preparation achieved greater progress in tasks requiring more sophisticated involvement of cognitive processes, whereas the control group with common method of preschool preparation achieved greater progress in mechanic skills. Although these findings should be replicated with larger sample, they support implementation of dynamic assessment based preschool preparation, because they stress the importance of orientation on the cognitive and metacognitive processes. 
Table 5. Mean progress in all tested area-results

\begin{tabular}{|c|c|c|c|c|c|c|c|c|c|}
\hline & Shapes & Writing & Dots & Pre-math. & Visual perc. & Visual dif. & Auditroyperc. & Articultion & Total \\
\hline $\begin{array}{l}\text { Experimental groups } \\
\mathrm{N}=30\end{array}$ & 3.1 & 7.36 & 2.85 & 0.83 & 2.99 & 8.4 & 10.36 & 5.56 & 42.5 \\
\hline $\begin{array}{l}\text { Control groups } \\
\mathrm{N}=26\end{array}$ & 5.19 & 7.9 & 4.56 & 0.77 & 2.65 & 3.92 & 2.38 & 5.3 & 32.28 \\
\hline
\end{tabular}

\subsection{Utility of the VIG Method in Implementation of Dynamic Assessment-Based Preschool Preparation}

It can be assumed that an implementation of the dynamic assessment-based preschool preparation by the VIG method reflects the principle of scaffolding. It comes out from the specific needs and communication sources of the teacher. On the recordings, the teacher can see herself successfully using the principles of dynamic assessment whereby she verifies the efficiency of those principles. Simultaneously, she increases her sensitivity to the communication signals of children.

Based on the observation of learning styles of teacher in both groups, implementation of dynamic assessment-based preschool preparation was more efficient in the stage 2, in which the VIG method had been used. In the stage 1, teachers were educated in dynamic assessment techniques only by short course in Educational Psychology Service. This form of education (in comparison with VIG) lacks level of experience and the possibility of long-term observation and regulation of learning style of the teacher to follow the ideas of dynamic assessment. Teachers in stage 2 seemed to be much more interested in dynamic assessment. One of them even stated that this kind of intervention (implementation of dynamic assessment with the help of VIG) "changed her life", because she started to use more intensively cognitive and metacognitive processes.

By both teachers, a control recording has been implemented after approximately three years. The objective was to verify a time-stability of acquired principles in learning styles of the teachers. Both teachers were still using principles of dynamic assessment in their education. On control recordings, we did not identified all principles that teacher used during a work with the VIG method. This finding is comprehensible because in a research, both teachers had been recorded three times, so we had much more of recorded situations, in which the principles could be applied. We identified more of DA principles by the teacher 1 who proved higher motivation and involvement and less of nervousness during the work with the VIG method. This finding demonstrated that the implementation of dynamic assessment-based preschool preparation by the VIG method significantly depends on the personality of a teacher. Table 6 summarizes principles of VIG identified during control recording by both teachers.

Table 6. Principles application identified by control recording

\begin{tabular}{ll}
\hline Teacher 1 & Teacher 2 \\
\hline mediation for transcendence & mediation for transcendence \\
mediation for reciprocity & designation of cognitive strategies \\
mediation for feeling of competence & more of communication exchanges \\
designation of cognitive strategies & \\
more space for thinking and expressing of a response & \\
more of short communication exchanges & \\
learning in the zone of proximal development & \\
\hline
\end{tabular}

\section{Discussion}

The research maps possibilities of implementation of dynamic assessment in kindergartens in Czech Republic, where the dynamic assessment is quite new and uncovered area. The long-term intensive study verified effectiveness of dynamic assessment based preschool preparation in comparison with traditional methods. Based on research findings, the paper summarizes two possible ways of implementation of dynamic assessment in schools-short course in Educational Psychology Service and work with the VIG method, comparing their 
usefulness for teachers. The research also identified importance of principles of dynamic assessment in learning styles of teachers and investigated conditions of their successful implementation (stability in time etc.).

There were some undesirable influences in the research, maturation and learning, resulting from the duration of research stages (one school year in first and second stage). Nevertheless, these influences have been inhibited by inclusion of control groups.

The next undesirable influence was the experimental mortality resulted from an optional school attendance in kindergartens in Czech Republic, but the resultant size of samples corresponds to qualitative and intensive character of the study. In future, the research (or its parts) could be replicated with broader sample size to confirm significance of some findings. Future research could also take advantage from dynamic methods evaluating efficiency of dynamic assessment-based preschool preparation. This research used as evaluative instrument a static method, because in the time of its realization, there were any suitable dynamic methods available in Czech Republic. Recently, The Application of Cognitive Functions Scale (Haywood \& Lidz, 2007) has been translated, localized and in 2014 published in Czech Republic. Using of this diagnostic instrument could significantly enrich our findings.

Despite all mentioned advantages of dynamic assessment, many authors state that this approach is relatively expensive and time-consuming (e.g. Tzuriel, 2001; Landor, 2006). Because of these disadvantages, researches should demonstrate that dynamic assessment can reveal the learning potential of an individual much more effectively than static methods and simultaneously can enhance cognitive strategies to make the real learning potential of the individual apparent and available.

\section{References}

Beaufortová, K. (2002). Videotrénink interakci (základy metody a její využití) (Video InteractionGuidance-basicsofthemethod and itsutilization). Prague: SPIN CZ.

Bidlová, E. (2005). Sociální dovednosti učitele a možnosti jejich rozvíjení (Social Skills of Teachers and Possibilities of Their Development) (Unpublished doctoral dissertation). Charles University in Prague, Czech Republic.

Caffrey, E., \& Fuchs, D., \& Fuchs, L. (2008). The Predictive Validity of Dynamic Assessment: A Review. The Journal of Special Education, 41(4), 254-270. http://dx.doi.org/10.1177/0022466907310366

Feuerstein, R., Klein, S. P., \& Tannenbaum, J. T. (1991). Mediated Learning Experience (MLE): Theoretical, Psychosocial and Learning Implication. Tel Aviv: Freund Publishing House Ltd.

Forsyth, P. (2008). The development of student teachers' interaction skills: Is it time to re-think? Faculty of Education and Social work, University of Dundee, Scotland.

Fukkink, R. G. (2008). Video feedback in widescreen: A meta-analysis of family programs. Clinical Psychology Review, 28(6), 904-916. http://dx.doi.org/10.1016/j.cpr.2008.01.003

Fukkink, R., \& Tavecchio, L. (2010). Effect of Video Interaction Guidance on early childhood teachers. Teaching and Teacher Education, 26(8), 1652-1659. http://dx.doi.org/10.1016/j.tate.2010.06.016

Häggman-Laitila, A. \& Pietilä, A. M., Friis, L., \& Vehviläinen-Julkunen, K. (2003). Video home training as a method of supporting family life control. Journal of Clinical Nursing, 12(1), 93-106. http://dx.doi.org/10.1046/j.1365-2702.2003.00696.x

Haywood, C., \& Lidz, C. (2007). Dynamic Assessment in Practice. Clinical and Educational Applicationc. New York, NY: Cambridge University Press.

Haywood, C., \& Tzuriel, D. (2002). Applications and Challenges in Dynamic Assessment. Peabody Journal of Education, 77(2), 40-63. http://dx.doi.org/10.1207/S15327930PJE7702_5

Kozulin, A. (1998). Psychological Tools. A Sociocultural Approach to Education. London: Harvard University Press.

Kozulin, A. (2003). Psychological Tools and Mediated Learning. In A. Kozulin et al. (Eds.), Vygotsky's Educational Theory in Cultural Context. New York, NY: Cambridge University Press.

Kozulin, A., \& Garb, E. (2004). Dynamic assessment of literacy: English as a third language. European Journal of Psychology of Education, 19(1), 65-77. http://dx.doi.org/10.1007/BF03173237

Landor, M. (2006). An exploration of the perceived effects of giving verbal and video feedback to the child, following dynamic assessment (Unpublished diploma thesis). University of Dundee, Dundee, Scotland. 
Lidz, C. (1991). Practitioner's Guide to Dynamic Assessment. New York, NY: Guilford Press.

Mattarima, K., \& Hamdan, A. R. (2011). Understanding Students Learning Strategies as an Input Context to Design English Classroom Activities. International Journal of Psychological Studies, 3(2), 238-248. http://dx.doi.org/10.5539/ijps.v3n2p238

Sternberg R. J., \& Grigorenko E. L. (2002). Dynamic Testing. The Natue and Measurement of Learning Potential. New York, NY: Cambridge University Press.

Strnádková, J. (2005). Př́spěvek k dynamickédiagnosticepredš̌kolnichdětí (Paper to the dynamic diagnostics of pre-school children) (Unpublished diploma thesis). Prague, Charles University in Prague, Czech Republic.

Šebová, A. (2004). Screening konvenčnichukazatelůškolnizralosti a připravenostipředškoláků v modřanských MŠ (Screening of conventional indicators of school maturity and readiness in kindergartens in Modřany) (Unpublished graduate thesis in Innovative Course of School Psychology). Charles University in Prague, Czech Republic.

Šilhánová, K. (2008). Manuál pro VTI ve škole (Manualfor VIG in School). Prague, SPIN CZ.

Šírová, E., \& Krejčová, K. (2011). The Role of the Video Interaction Guidance in the Enrichment of Student Teachers' Social Skills. Journal on Efficiency and Responsibility in Education and Science, 4(4), 162-169.

Tzuriel, D. (2001). Dynamc Assessment of Young Children. New York, NY: Kluwer Academic/Plenum Publishers.

Vygotskij, L. S. (1986). Thought and Language. Cambridge, MA: MIT Press.

Wilcoxon, F. (1945). Individual Comparisons by Ranking Methods. Biometrics Bulletin, 1(6), 80-83. http://dx.doi.org/10.2307/3001968

\section{Copyrights}

Copyright for this article is retained by the author(s), with first publication rights granted to the journal.

This is an open-access article distributed under the terms and conditions of the Creative Commons Attribution license (http://creativecommons.org/licenses/by/3.0/). 